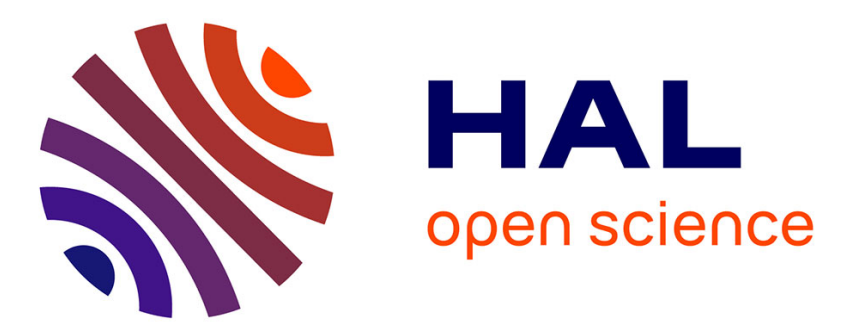

\title{
A simple method to minimize displacement measurement uncertainties using dynamic nanoindentation testing
}

Gaylord Guillonneau, Guillaume Kermouche, Sandrine Bec, Jean-Luc Loubet

\section{- To cite this version:}

Gaylord Guillonneau, Guillaume Kermouche, Sandrine Bec, Jean-Luc Loubet. A simple method to minimize displacement measurement uncertainties using dynamic nanoindentation testing. Tribology International, 2014, 70, pp.190-198. 10.1016/j.triboint.2013.10.013 . emse-01161450

\section{HAL Id: emse-01161450 \\ https://hal-emse.ccsd.cnrs.fr/emse-01161450}

Submitted on 8 Sep 2021

HAL is a multi-disciplinary open access archive for the deposit and dissemination of scientific research documents, whether they are published or not. The documents may come from teaching and research institutions in France or abroad, or from public or private research centers.
L'archive ouverte pluridisciplinaire HAL, est destinée au dépôt et à la diffusion de documents scientifiques de niveau recherche, publiés ou non, émanant des établissements d'enseignement et de recherche français ou étrangers, des laboratoires publics ou privés.

\section{(c)(1)}

Distributed under a Creative Commons Attribution| 4.0 International License 


\title{
A simple method to minimize displacement measurement uncertainties using dynamic nanoindentation testing
}

\author{
G. Guillonneau ${ }^{\mathrm{a}, *}$, G. Kermouche ${ }^{\mathrm{b}}$, S. Bec ${ }^{\mathrm{c}}$, J.-L. Loubet ${ }^{\mathrm{c}}$

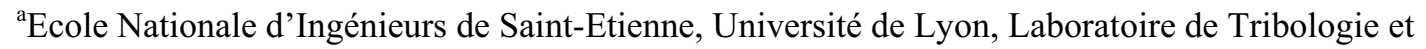 \\ Dynamique des Systèmes, UMR 5513 CNRS/ECL/ENISE, 42000 Saint-Etienne, France \\ ${ }^{\mathrm{b}}$ Ecole des Mines de Saint-Etienne, Centre SMS, Laboratoire LGF UMR 5307, 158 Cours Fauriel \\ 42023 Saint-Etienne, France \\ ${ }^{c}$ Ecole Centrale de Lyon, Université de Lyon, Laboratoire de Tribologie et Dynamique des Systèmes, \\ UMR 5513 CNRS/ECL/ENISE, 69134 Ecully, France \\ *Corresponding author. Tel.: +33(0)477437542. \\ E-mail address: gaylord.guillonneau@enise.fr (G. Guillonneau)
}

\begin{abstract}
A new simple indentation method is presented, minimizing strongly the influence of uncertainties linked to the displacement measurement, in the context of homogeneous materials indented by a sharp tip. Based on the determination of the derivative of the contact depth with respect to the indentation depth, this method depends indirectly on the displacement measurement, making the technique less sensible to displacement uncertainties. After being validated on flat samples (fused silica, PMMA), the method was tested on a rough specimen (anodized aluminum, $\mathrm{Ra}=1.7 \mu \mathrm{m}$ ) and on two heated flat samples (fused silica, PMMA, $60^{\circ} \mathrm{C}$ ). The mechanical properties determined by this new technique are more precise than properties measured by classical nanoindentation measurement.
\end{abstract}

\section{Keywords}

Hardness, Nanoindentation, Rough samples, High temperature. 


\section{Introduction}

Subsurface measurement of hardness and elastic modulus is of primary importance for tribological applications. For instance, most of wear laws are based on the hardness of contacting surfaces and elasto(plasto)hydrodynamic applications are strongly affected by both the hardness and the elastic modulus [1]. The nanoindentation technique is the most popular technique to determine the surface mechanical properties of materials [2]. The principle consists in applying a small normal load to an indenter of known geometry, and to record the applied load and the penetration of the indenter. The technique can be used to measure surface mechanical properties of homogeneous materials or layered

materials $[3,4]$. The main mechanical properties measured by nanoindentation are the hardness $H$ and the elastic modulus $E[5-8]$ :

$$
\begin{aligned}
& H=\frac{P}{A_{c}} \\
& E_{c}^{* *}=\frac{S}{2} \sqrt{\frac{\pi}{A_{c}}} \\
& \frac{1-v^{2}}{E}=\frac{1}{E_{c}^{* *}}-\frac{1-v_{i}^{2}}{E_{i}^{*}}
\end{aligned}
$$

Where $P$ is the applied load, $A_{c}$ is the projected contact area, $E_{c}^{* *}$ is the contact elastic modulus, $E_{i}^{* *}$ is the reduced elastic modulus of the indenter, and $v$ and $v_{i}$ are the Poisson ratio of the sample and the indenter respectively. $S$ is the harmonic contact stiffness which can be measured at maximum load by a static method or continuously versus the indentation depth with a dynamic method (often called Continuous Stiffness Measurement [9]). The projected contact area $A_{c}$ is related to the contact depth $h_{c}$ with the following geometrical relation (for a perfect pyramidal indenter):

$$
A_{c}=\pi \tan ^{2}(\theta) h_{c}^{2}
$$


Where $\theta$ is the angle of the equivalent conical indenter. The relation between the contact depth and the indentation depth is non-trivial. Pile-up or sink-in phenomena have to be taken into account, in relation with material behavior. Up to date, there is no general method that bypasses this problem. There exists also a second source of uncertainties that needs to be considered to perform accurate nanoindentation measurements. They are linked to indentation displacement measurement. For instance, the thermal drift can induce uncertainties on the displacement measurement [10]. There exist some procedures to correct the thermal drift when indentations are performed at room temperature, but, at non-ambient temperature, the thermal drift is too important and perturbs greatly the displacement measurement and so, the determination of mechanical properties. In a recent paper, we have proposed a new method to reduce these uncertainties by using the measurement of second harmonic amplitude of the dynamic indentation signal [11]. Nevertheless, this technique requires to adapt the apparatus instrumentation, which is not accessible for most of standard users. Another uncertainty is linked to the surface roughness. Indenting a rough surface may cause difficulties to extract precisely the mechanical properties by nanoindentation $[12,13]$. Since the contact may occur on a peak or a valley, the determination of the contact depth at small penetration depth may vary strongly depending on the indentation location $[14,15]$. To avoid such a problem, it is recommended to indent at high depth in order to minimize the roughness effect, or to polish the sample, but mechanical polishing modifies the hardness near the surface $[16,17]$. Some authors have developed methods in order to minimize the roughness influence on measured properties but most of these techniques require a large number of experiments [18-20].

All of these uncertainties are encountered in the context of tribological applications. For instance, a lot of systems work at non-ambient temperature or friction can induce near-surface temperature elevation, thus it is necessary to determine accurately the nano-hardness as a function of temperature to predict the wear evolution. Measuring elastoplastic properties of rubbed surfaces often imposes to cope with rough surfaces too. Therefore the development of new instrumented indentation methods in these difficult experimental conditions will help to obtain more reliable and accurate values of near-surface mechanical properties for tribological studies. 
In this paper, a simpler method is presented, usable without any additional instrumentation, to minimize these uncertainties. This new method is based on the calculation of the derivative of the contact depth with respect to the indentation depth. First, the new expressions used to measure the mechanical properties are presented. Then, an experimental validation of the method on well-known and prepared samples is given. In the last part, examples of applications on a rough sample and at high temperature are detailed and discussed.

\section{Theory}

\subsection{Standard methods}

When a homogeneous material is indented by a perfectly sharp tip, the dynamic contact stiffness $S$ is expected to be proportional to the indentation depth $h$, and the hardness and the elastic modulus are independent of the applied load $[3,21]$ :

$S=2 E_{c}^{*} \tan (\theta) h_{c}$ with $h_{c}$ proportional to $h$

In this case, the ratio of load divided by squared contact stiffness is also independent of the applied load and is given by [21]:

$\frac{P}{S^{2}}=\frac{H \pi}{4\left(E_{c}^{*}\right)^{2}}$

Because this ratio is obtained directly from measured values, it is not affected by displacement measurement uncertainties. But, to go further, a second equation is required to determine the hardness and the elastic modulus. Generally, the chosen equation relates the contact depth to the indentation depth as proposed for example by Loubet et al. [22-24]:

$h_{c}=\alpha\left(h-\frac{P}{S}+h_{0}\right)$

Where $\alpha$ is a constant related to pile-up or sink-in which is equal to 1.2 for a Berkovich indenter, and $\mathrm{h}_{0}$ is the equivalent height of the tip defect. This coefficient can be easily calculated by plotting the 
harmonic contact stiffness $S$ as a function of the plastic depth $h_{r}$, as shown in Fig. 1, with $h_{r^{\prime}}=h-P / S$. With Eq. (7), it is clear that any errors related to the indentation depth measurement will strongly affect the calculation of hardness and Young modulus values.

\subsection{An alternative method for homogeneous materials}

Taking advantage of Eq. (7), the derivative of the contact depth with respect to the indentation depth appears to be independent of the indentation depth and the tip defect $h_{0}$. From Eqs. (5), (6) and (7), we obtain:

$h_{c}=\alpha\left(h-\frac{H \pi \tan (\theta)}{2 E_{c}^{*}} h_{c}+h_{0}\right)$

$\frac{d h_{c}}{d h}=\frac{\alpha}{1+\frac{\alpha H \pi \tan (\theta)}{2 E_{c}^{*}}}$

In this expression, the coefficients $\alpha$ and $\theta$ are known. The term $d h_{c} / d h$ can be determined by a simple linear fit. Consequently, the ratio $H / E_{c}^{* *}$ can be computed with the following equation:

$$
\frac{H}{E_{c}^{* *}}=\frac{2}{\pi \tan (\theta)}\left(\frac{1}{\frac{d h_{c}}{d h}}-\frac{1}{\alpha}\right)
$$

Combining with Eq. (6), the hardness and the elastic modulus are now given by:

$$
\begin{aligned}
& E_{c}^{* *}=\frac{S^{2}}{2 P \tan (\theta)}\left(\frac{1}{\left.\frac{d h_{c}}{d h}-\frac{1}{\alpha}\right)}\right. \\
& H=\frac{4 P\left(E_{c}^{* *}\right)^{2}}{\pi S^{2}}
\end{aligned}
$$


Where $E_{c}^{\prime *}$ is calculated with Eq. 11. Similarly to the second harmonic method, thermal drifts effects should thus be minimized, because the calculations are not directly related to the absolute measurement of the indentation depth. Moreover, it can be noticed that the indenter tip defect estimation is no more necessary and the identification of the initial contact point has less influence on results. Nevertheless, this method can be used only if the indented material is homogeneous at the indentation scale to take advantage of the linear dependence of the contact depth with respect to the indentation depth. For instance, it is not possible to use such an approach when considering the indentation of thin films on substrates. Nevertheless, standard contact models also fail in this case as shown by Perriot et al [25].

In this paper the expressions (11) and (12) have been derived from the Loubet contact model but the extension to the Oliver and Pharr contact model does not induce any additional difficulties if the indenter tip defect introduced by Loubet et al. is used instead of the area function classically used to compute the projected contact area $[3,24]$ :

$h_{c}=h-\varepsilon \frac{P}{S}+h_{0}$

Where $\varepsilon$ is a constant parameter. In this case, the hardness and elastic modulus are expressed by the following equations:

$E_{c}^{* *}=\frac{S^{2}}{2 \varepsilon P \tan (\theta)}\left(\frac{1}{\frac{d h_{c}}{d h}}-1\right)$

$$
H=\frac{4 P\left(E_{c}^{* *}\right)^{2}}{\pi S^{2}}
$$

Where $E_{c}^{* *}$ is calculated with Eq. 14.

2.3. A new simple indentation procedure 
The test procedure is similar to standard nanoindentation experiments based on the standard dynamic mode (CSM). The main difference results in the calculation of the mechanical properties which now requires the determination of $d h_{d} / d h$. This can be computed locally by determining the local slope of the $h_{c}-h$ curve, or it can be computed globally from the entire $h_{c}-h$ curve, with $h_{c}$ calculated with the Loubet model or the Oliver and Pharr model (Eq. 7 and 13) and the first contact point is determined as the origin of the contact stiffness-indentation depth curve [21]. We suggest here to use the global slope of the $h_{c}-h$ curve because this coefficient is less affected by uncertainties at low indentation depth (rough samples, indenter tip defect). This implies that results obtained at small indentation depth have to be considered with caution. The same observation can be done considering the calculation of $P / S^{2}$. As this ratio is not strongly affected by thermal drift or other displacement uncertainties and is not obtained by derivation, it is proposed to use its local value to compute the mechanical properties.

It is important to note that this method is limited to materials for which the ratio $H / E_{c}^{* *}$ does not depend on the indentation depth. For example, it means that the method is unable to characterize correctly ISE materials and layered materials. Before computing hardness and elastic modulus with this technique, it is necessary to check that the harmonic contact stiffness $S$ is proportional to the indentation depth, and that the $P / S^{2}$ ratio is approximately constant over the indentation depth range of interest.

\section{Application to smooth samples: fused silica and PMMA}

In order to validate the method described above, experiments were performed on two well-known smooth and homogeneous materials at ambient temperature: fused silica and PMMA. A Nano Indenter SA2 ${ }^{\circledR}$ equipped with a DCM head system (Agilent Technologies) was used. This load-controlled apparatus has high resolution in displacement and force measurements ( $0.2 \mathrm{pm}$ and $1 \mathrm{nN}$ respectively). A Berkovich diamond tip was used in the experiments. The equivalent height of the tip defect $h_{0}$ was approximately $5 \mathrm{~nm}$. For more details about the apparatus and materials, please refer to Guillonneau et al. [10]. The maximum applied load on the specimens was $10 \mathrm{mN}$. The oscillation amplitude was set 
to $1 \mathrm{~nm}$. The oscillation frequency was $75 \mathrm{~Hz}$ for fused silica, and $31 \mathrm{~Hz}$ for PMMA. The strain rate was constant by imposing $\dot{P} / P=0.03 s^{-1}$. Ten indentation tests were performed on each sample.

Fig. 2 presents the evolution of the harmonic contact stiffness $S$ and the $P / S^{2}$ ratio as a function of the indentation depth $h$. In agreement with the theory, $S$ is proportional to the indentation depth from 10$20 \mathrm{~nm}$ and $P / S^{2}$ is constant from $h_{j}=50 \mathrm{~nm}$. Consequently, Eqs. (11) and (12) can be used to compute the mechanical properties for indentation depths higher than $50 \mathrm{~nm}$. Fig. 3 shows the contact depth evolution as a function of the indentation depth, the contact depth being calculated with the Loubet model. As expected, the contact depth is proportional to the indentation depth, so the $d h_{c} / d h$ value is easily calculable. The same observation is done when the contact depth is calculated with the Oliver and Pharr model but the curves are not presented here for the clarity of the paper. Figs. 4 and 5 compare the hardness and reduced Young modulus mean values versus indentation depth, calculated from the classical standard method and according to the method developed in this paper. The properties are determined with the Loubet model and the Oliver and Pharr model. A very good agreement is observed in the indentation depth range for where $P / S^{2}$ is constant. One can observe, in the case of PMMA sample (Fig. 5), that the obtained properties are different if the properties are determined with the Loubet model or the Oliver and Pharr model. This difference highlights the difficulty in determining the true contact area under load which depends on the chosen model. But this problem is independent of the method developed in this paper. In the case of PMMA, the absence of pile-up in the Oliver and Pharr method induces an underestimation of the contact area. On the contrary, the Loubet model induces an overestimation. Thanks to its high $H / E$ ratio, it is well known that results on fused silica are less affected by the contact model choice, which explains why there is no difference between the two models. The determination of the true contact area under load is still an important challenge in nanoindentation testing but it is not within the scope of the present paper. 


\section{Application to difficult experimental conditions}

\subsection{Rough sample}

It is well known that sample surface has to be as smooth as possible to determine the mechanical properties with the best accuracy. In some cases, polishing the surface by mechanical or electrochemical methods may induce changes in the hardness value near the surface [26], which is prejudicial for the interpretation of nanoindentation measurements. To avoid such problems, it is recommended to pay attention to the surface preparation. Nevertheless it is difficult to state on the surface polishing quality before making the indentation experiments. In the next paragraph, it is shown that the application of the proposed method on a rough sample permits to determine a first set of mechanical properties without requiring any mechanical polishing

Experiments performed on a sample made on anodized aluminum sample $(\mathrm{Ra}=1.7 \mu \mathrm{m}$, see Fig. 6$)$ are presented. A Nano Indenter XP ${ }^{\circledR}$ (Agilent Technologies) was used [27]. This load-controlled apparatus has lower resolution in displacement and force measurement $(0.5 \mathrm{~nm}$ and $10 \mathrm{nN}$ respectively) but higher load indentations $\left(P_{\max }=450 \mathrm{mN}\right)$ can be performed. A Berkovich diamond tip was used in the experiments. The equivalent height of the tip defect $h_{0}$ was approximately $15 \mathrm{~nm}$. The maximum load applied to the specimen was $450 \mathrm{mN}$. The oscillation amplitude was set to $1 \mathrm{~nm}$. The oscillation frequency was $32 \mathrm{~Hz}$. Constant strain rate was obtained with $\dot{P} / P=0.03 \mathrm{~s}^{-1}$. Ten indentation tests were performed on this sample.

Fig. 7 presents the evolution of the harmonic contact stiffness $S$ and $P / S^{2}$ ratio as a function of the indentation depth $h$. As expected, from $h_{j}=500 \mathrm{~nm}$ the stiffness $S$ varies linearly versus indentation depth and $P / S^{2}$ is constant. Thus, the hardness can be calculated according to Eqs. (11) and (12). Moreover, as shown in Fig. 8, like for flat samples, the value of $d h_{c} / d h$ is easily calculable with a linear fit. As shown in Fig. 9, a larger scattering is observed when the standard method is used. With the new method proposed in this paper, the scattering is strongly reduced, and a mean hardness value can be extracted with more accuracy. Our interpretation is that the effects of roughness on the 
indentation depth are minimized thanks to the linear fit of the $h_{c}-h$ curve. This result is of primary importance because it highlights that it is possible to estimate the hardness of rough samples without any specific surface preparation.

\subsection{Tests at non ambient temperature}

During the past decade, important efforts have been devoted to the development of nanoindentation experiments under high temperature environment [28]. One of the most important challenges is to minimize the thermal drift induced by the device thermal regulation, which affects more specifically the indentation depth during the test. For instance, Fig. 10.a) shows load-displacement curves corresponding to ten nanoindentation experiments performed on a fused silica sample heated at $60^{\circ} \mathrm{C}$. These bad results are mainly due to the thermal regulation during the test which affects the displacement measurement. Nevertheless, it can be observed on Fig. 10.b) that the harmonic contact stiffness and the load are not perturbed by thermal regulation, which implies that the method proposed in this paper will be less affected by the thermal regulation.

In this section, experiments performed on fused silica and PMMA samples at non-ambient temperature are presented. The Nano Indenter $\mathrm{XP}{ }^{\circledR}$ (Agilent Technologies) was used with a Berkovich diamond tip. The equivalent height of the tip defect $h_{0}$ was approximately $15 \mathrm{~nm}$. This apparatus is equipped with a sample heater. Electrical components are protected by a thermal shield. One important drawbacks of this device is that the indenter can only be heated by contact with the sample, which results in an increase of the drift due to thermal dilation [29]. To minimize this effect, a test procedure proposed in the literature has been used. It consists in contacting the tip with the sample at very low load $(100 \mu \mathrm{N})$ during approximately 3 hours, before making the indentation without losing the contact between the tip and the sample [30]. Further information about the apparatus are given in the documentation [27]. The maximum load applied to the specimens was $450 \mathrm{mN}$ for fused silica sample and $300 \mathrm{mN}$ for PMMA sample. The oscillation amplitude was set to $1 \mathrm{~nm}$. The oscillation frequency was $32 \mathrm{~Hz}$. The strain rate was constant with $\dot{P} / P=0.03 \mathrm{~s}^{-1}$. Ten indentation tests were performed on 
each sample. The test temperature was $60^{\circ} \mathrm{C}$. The tip heating procedure was used for each indentation test.

As shown on Figs. 11 and 12, the harmonic contact stiffness is linear and the $P / S^{2}$ ratio is constant versus the indentation depth from $h_{j}=250 \mathrm{~nm}$, in spite of the thermal drift which affects the displacement measurement. Consequently, the hardness can be calculated using Eqs. (11) and (12). In Figs. 13.a) and 14.a), a large scattering is observed on the hardness curve obtained from the classical method. Better results are obtained with the proposed method based on $d h_{c} / d h$ calculation (Figs. 13.b) and 14.b)). The explanation of these better results is illustrated on Fig. 15 showing $h_{c}-h$ curves for fused silica and PMMA samples (mean value of 10 indents). As it can be seen, the contact depth is linear versus indentation depth. Consequently, the value of $d h_{c} / d h$ is easily calculable, and the mechanical properties are more precisely measured with this method.

\section{Conclusion}

In this paper, a new method is proposed to extract mechanical properties from nanoindentation testing. It is based on the calculation of the derivative of the contact depth with respect to the indentation depth, which is simply obtained from the slope of a linear fit of the $h_{c}-h$ curve. As the method is no longer dependent of the absolute indentation depth measurement, it is less sensible to thermal drift, surface roughness, and tip defect. Nevertheless, it is important to keep in mind that the equations have been obtained with the strong hypothesis that the indented material is homogeneous, i.e. that the harmonic contact stiffness is proportional to the indentation depth and that $P / S^{2}$ ratio is constant versus depth.

The application of the method on two smooth samples (fused silica and PMMA) at ambient temperature has provided results in good agreement with classical measurement. Nanoindentation tests performed on a rough anodized aluminum sample has shown that this new method gives more precise results. Finally, it was shown that hardness can be accurately measured with this new method in the context of nanoindentation at elevated temperature whereas the standard method leads to strongly 
scattered results. The main advantage of this method is that the global slope of the $h_{c}$ - $h$ curve is less affected by the sample roughness or by the thermal regulation than the standard one based on the absolute indentation depth measurement.

Thanks to these developments, it makes it possible for users of standard nanoindentation device to measure accurate mechanical properties in difficult experimental conditions such as not ambient temperature and rough samples.

\section{References}

[1] Georges J-M. Frottement, usure et lubrification: La tribologie ou science des surfaces. Eyrolles; 2000.

[2] Fischer-Cripps AC. Nanoindentation. Springer-Verlag New York Inc.; 2002.

[3] Oliver WC, Pharr GM. An improved technique for determining hardness and elastic-modulus using load and displacement sensing indentation experiments. J Mater Res 1992;7:1564-83.

[4] Doerner MF, Nix WD. A method for interpreting the data from depth-sensing indentation instruments. J Mater Res 1986;1:601-9.

[5] Tabor D. The hardness of solids. Rev Phys Technol 1970;1:145-79.

[6] Sneddon IN. Relation between load and penetration in axisymmetric Boussinesq problem for punch of arbitrary profile. Int J Eng Sci 1965;3:47-57.

[7] Bulychev SI, Alekhin VP, Shorshorov MK, Ternovskii AP, Shnyrev GD. Determining Young modulus from the indenter penetration diagram. Ind Lab USSR Engl Transl Zavod Lab 1975;41:1409-12.

[8] Pharr GM, Oliver WC, Brotzen FR. On the generality of the relationship among contact stiffness, contact area, and elastic modulus during indentation. J Mater Res 1992;7:613-7.

[9] Asif SAS, Wahl KJ, Colton RJ. Nanoindentation and contact stiffness measurement using force modulation with a capacitive load-displacement transducer. Rev Sci Instrum 1999;70:2408-13.

[10] Guillonneau G, Kermouche G, Bec S, Loubet J-L. Extraction of mechanical properties with second harmonic detection for dynamic nanoindentation testing. Exp Mech 2012;52:933-44.

[11] Guillonneau G, Kermouche G, Bec S, Loubet J-L. Determination of mechanical properties by nanoindentation independently of indentation depth measurement. J Mater Res 2012;27:255160.

[12] Bobji M., Shivakumar K, Alehossein H, Venkateshwarlu V, Biswas S. Influence of surface roughness on the scatter in hardness measurements: a numerical study. Int J Rock Mech Min Sci 1999;36:399-404.

[13] Bobji MS, Biswas SK. Hardness of a surface containing uniformly spaced pyramidal asperities. Tribol Lett 1999;7:51-6.

[14] Miller M, Bobko C, Vandamme M, Ulm F-J. Surface roughness criteria for cement paste nanoindentation. Cem Concr Res 2008;38:467-76.

[15] Walter C, Mitterer C. 3D versus 2D finite element simulation of the effect of surface roughness on nanoindentation of hard coatings. Surf Coatings Technol 2009;203:3286-90.

[16] Donnelly E, Baker SP, Boskey AL, Van Der Meulen MCH. Effects of surface roughness and maximum load on the mechanical properties of cancellous bone measured by nanoindentation. $\mathrm{J}$ Biomed Mater Res A 2006;77:426-35.

[17] Grau P, Ullner C, Behncke H-H. Uncertainty of depth sensing hardness : Effect of roughness. Materialprüfung, vol. 39, Hanser; 1997, p. 362-7.

[18] Kim J-Y, Kang S-K, Lee J-J, Jang J, Lee Y-H, Kwon D. Influence of surface-roughness on indentation size effect. Acta Mater 2007;55:3555-62. 
[19] Bobji MS, Biswas SK. Deconvolution of hardness from data obtained from nanoindentation of rough surfaces. J Mater Res 1999;14:2259-68.

[20] Marteau J, Bigerelle M, Xia Y, Mazeran P-E, Bouvier S. Quantification of first contact detection errors on hardness and indentation size effect measurements. Tribol Int 2013;59:15462.

[21] Oliver WC, Pharr GM. Measurement of hardness and elastic modulus by instrumented indentation: Advances in understanding and refinements to methodology. J Mater Res 2004;19:3-20.

[22] Bec S, Tonck A, Georges J-M, Georges E, Loubet J-L. Improvements in the indentation method with a surface force apparatus. Philos Mag 1996;74:1061.

[23] Hochstetter G, Jimenez A, Loubet JL. Strain-rate effects on hardness of glassy polymers in the nanoscale range. Comparison between quasi-static and continuous stiffness measurements. $\mathrm{J}$ Macromol Sci Part B Phys 1999;38:681.

[24] Loubet JL, Bauer M, Tonck A, Bec S, Gauthier-Manuel B. Nano-indentation with a surface force apparatus. NATO Adv Study Inst Ser E 1993:429-47.

[25] Perriot A, Barthel E. Elastic contact to a coated half-space: Effective elastic modulus and real penetration. J Mater Res 2004;19:600-8.

[26] Liu Y, Ngan AH. Depth dependence of hardness in copper single crystals measured by nanoindentation. Scr Mater 2001;44:237-41.

[27] http://www.msm.cam.ac.uk/mechtest/docs/XP\%20User\%27s\%20Manual.pdf. 11.07.13; 2013.

[28] Chao Z, Hodge A. High-temperature nanoindentation: New developments and ongoing challenges. JOM J Miner Met Mater Soc 2009;61:32-6.

[29] Everitt NM, Davies MI, Smith JF. High temperature nanoindentation - the importance of isothermal contact. Philos Mag 2011;91:1221-44.

[30] Schuh CA, Packard CE, Lund AC. Nanoindentation and contact-mode imaging at high temperatures. J Mater Res 2006;21:725-36.

\section{Figures}

Fig. 1. Harmonic contact stiffness versus plastic depth for fused silica sample. The height of the tip defect is determined by extrapolating the stiffness curve on the plastic depth axis.

Fig. 2. a) Harmonic contact stiffness versus indentation depth for fused silica and PMMA samples: experimental curves and linear fits (10 indents). b) $P / S^{2}$ ratio versus indentation depth for fused silica and PMMA samples (10 indents).

Fig. 3. Contact depth versus indentation depth for fused silica and PMMA samples: experimental curves and linear fits. Each experimental point corresponds to the mean value calculated from ten tests performed on each sample.

Fig. 4. Comparison between mechanical properties of fused silica calculated classically and determined from $d h_{c} / d h$ value. a) Reduced elastic modulus and hardness versus indentation depth with 
$h_{c}$ calculated with the Loubet model. b) Reduced elastic modulus and hardness versus indentation depth with $h_{c}$ calculated with the Oliver and Pharr model.

Fig. 5. a) Comparison between mechanical properties of PMMA calculated classically and determined from $d h_{c} / d h$ value. a) Reduced elastic modulus and hardness versus indentation depth with $h_{c}$ calculated with the Loubet model. b) Reduced elastic modulus and hardness versus indentation depth with $h_{c}$ calculated with the Oliver and Pharr model.

Fig. 6. Image of the surface topography of the indented anodized aluminum sample obtained by laser interferometry.

Fig. 7. a) Harmonic contact stiffness versus indentation depth for anodized aluminum sample (10 indents). b) $P / S^{2}$ ratio versus indentation depth (10 indents).

Fig. 8. Contact depth versus indentation depth for anodized aluminum sample: experimental curve and linear fit. Each experimental point corresponds to the mean value calculated from ten tests performed on the sample.

Fig. 9. Mean and standard deviation of hardness versus indentation depth for anodized aluminum (10 indents). a) Classical calculation. b) Calculation with the use of $d h_{c} / d h$.

Fig. 10. a) Load versus indentation depth for fused silica sample indented at $60^{\circ} \mathrm{C}$ (10 indents).b) Harmonic contact stiffness versus load (10 indents).

Fig. 11. Harmonic contact stiffness versus indentation depth for fused silica (a) and PMMA (b) samples indented at $60^{\circ} \mathrm{C}(10$ indents).

Fig. 12. $P / S^{2}$ ratio versus indentation depth for fused silica (a) and PMMA (b) samples indented at $60^{\circ} \mathrm{C}(10$ indents).

Fig. 13. Mean and standard deviation of hardness versus indentation depth for fused silica sample indented at $60^{\circ} \mathrm{C}\left(10\right.$ indents). a) Classical calculation. b) Calculation with the use of $d h_{c} / d h$. 
Fig. 14. Mean and standard deviation of hardness versus indentation depth for PMMA sample indented at $60^{\circ} \mathrm{C}$ (10 indents). a) Classical calculation. b) Calculation with the use of $d h_{c} / d h$.

Fig. 15. Contact depth versus indentation depth for fused silica and PMMA samples at $60^{\circ} \mathrm{C}$ : experimental data and linear fit. Each experimental point corresponds to the mean value calculated from ten tests performed on each sample.

\section{Research highlights}

The new method is less sensible to nanoindentation thermal drift.

The new method is less sensible to contact point detection and tip defect.

Rough samples properties are more precisely measured with the new method.

Heated samples properties are more precisely measured with the new method. 


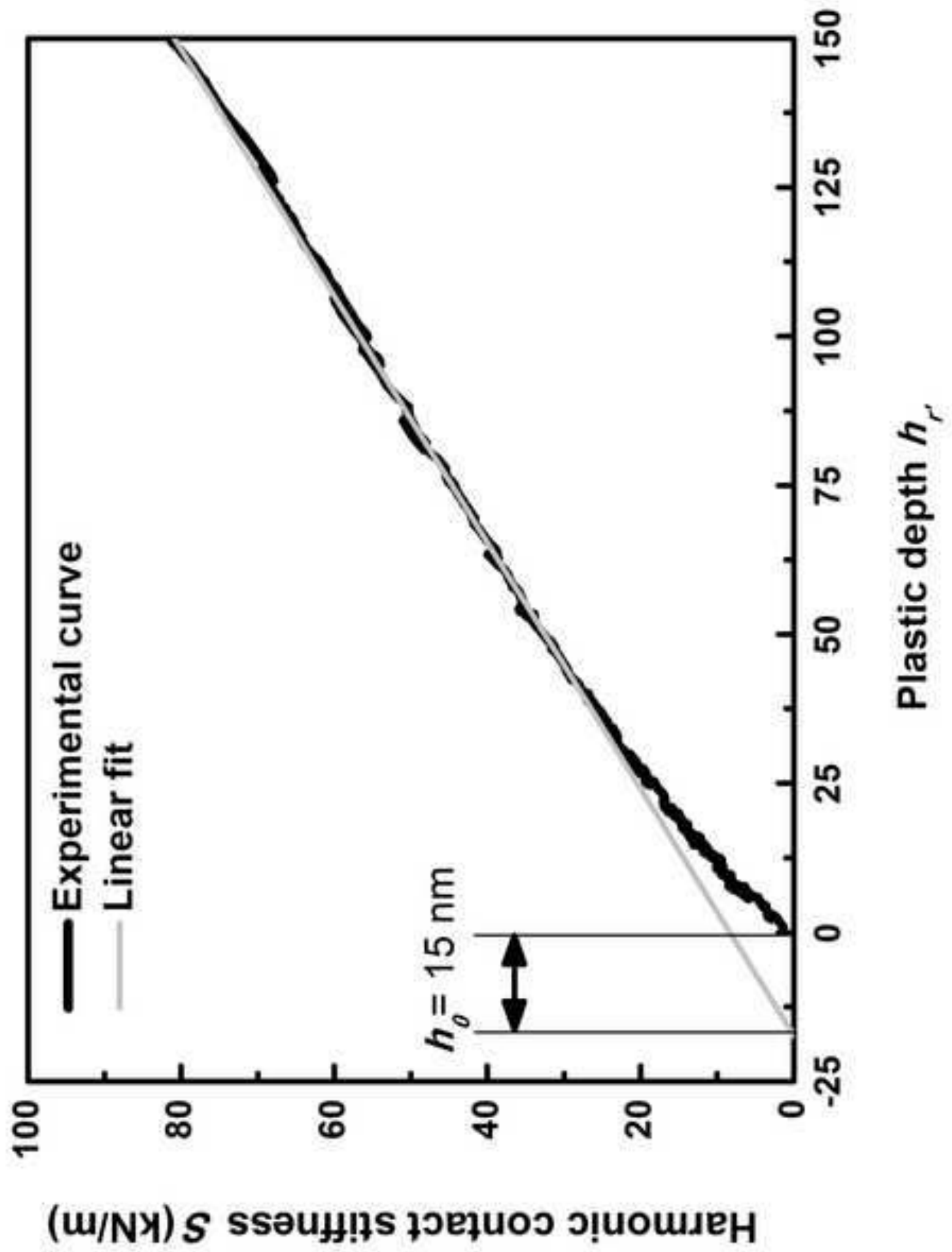

i் 
Fig. 2
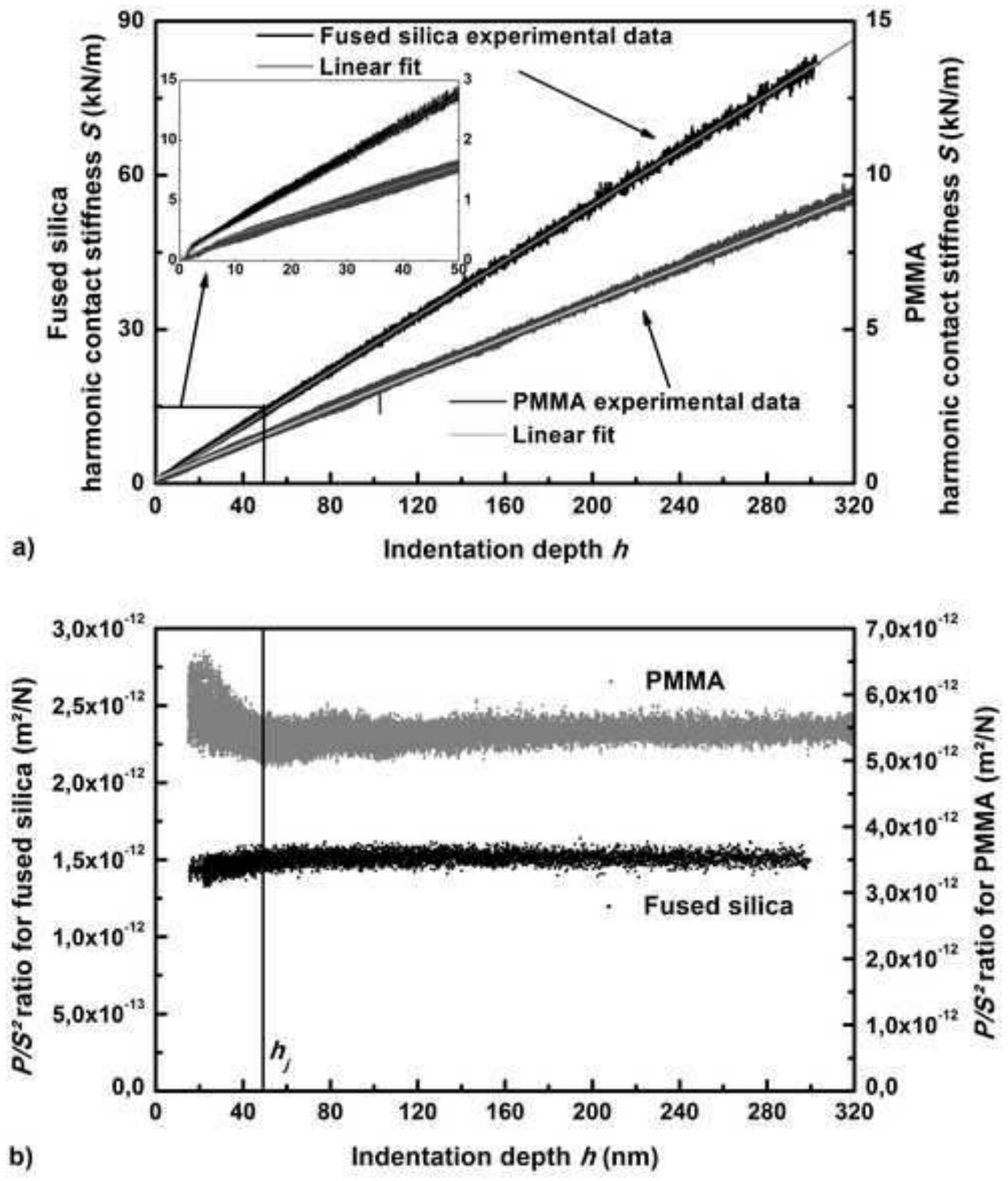


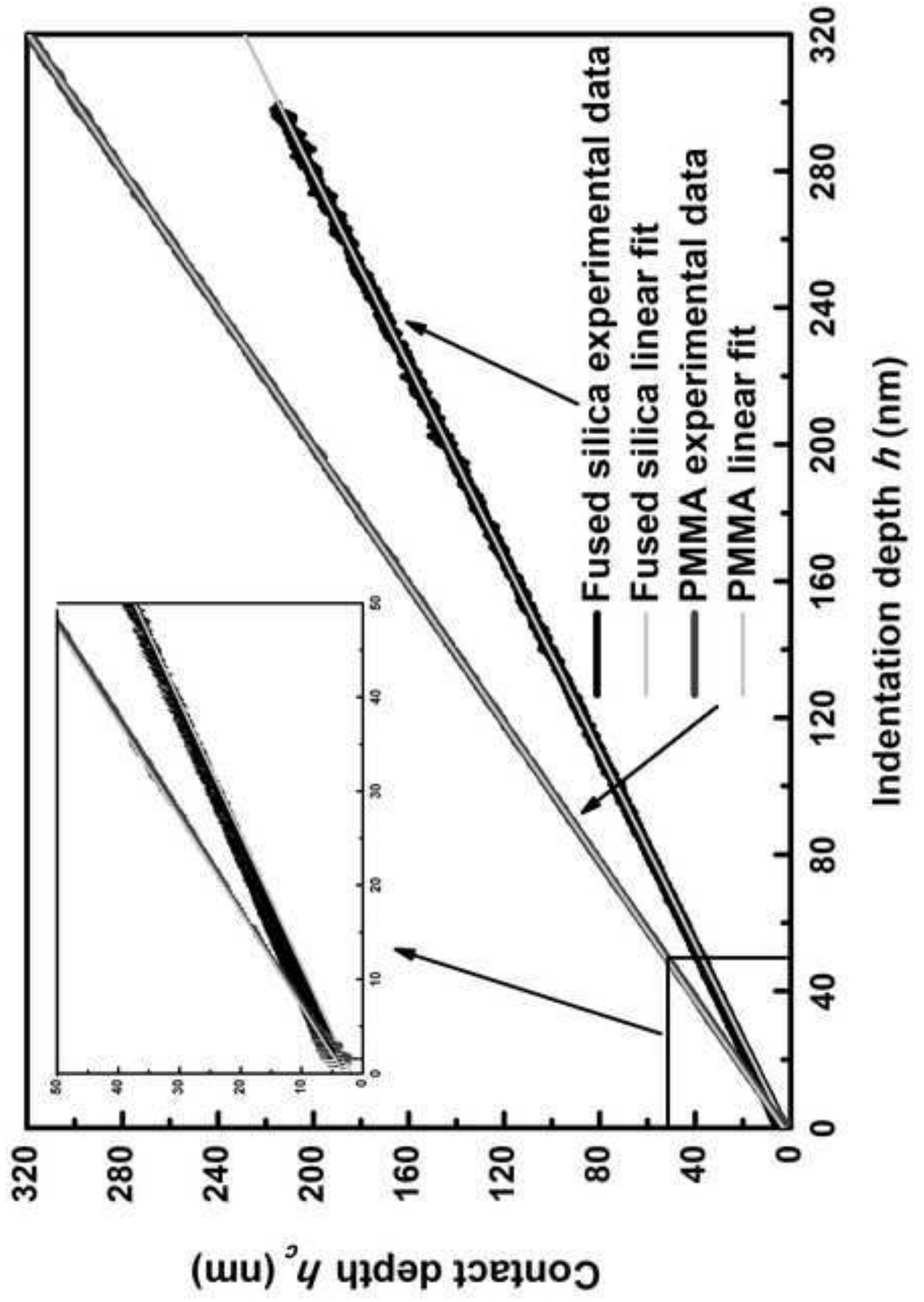


Fig. 4
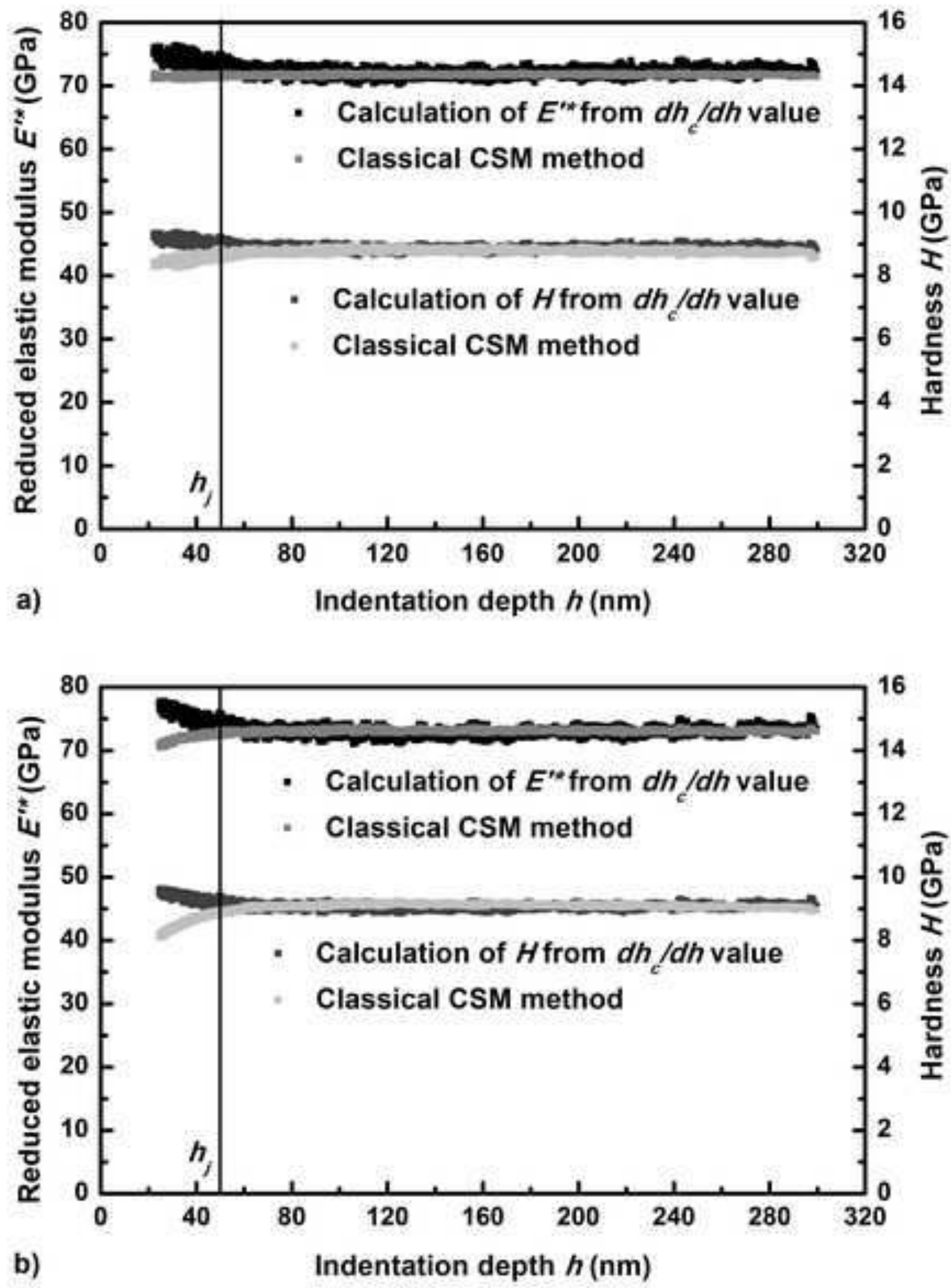
Fig. 5

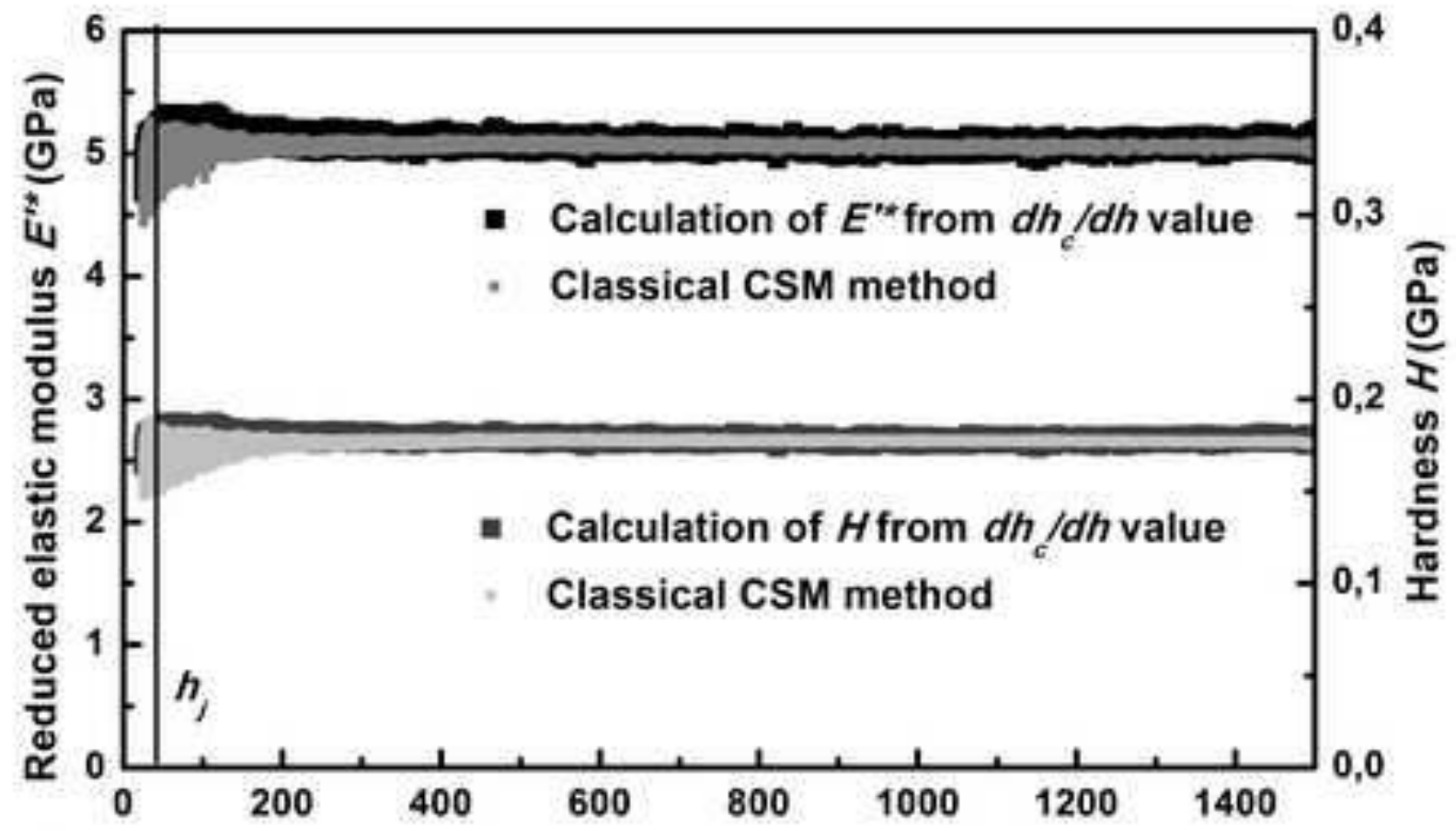

a)

Indentation depth $h(\mathrm{~nm})$

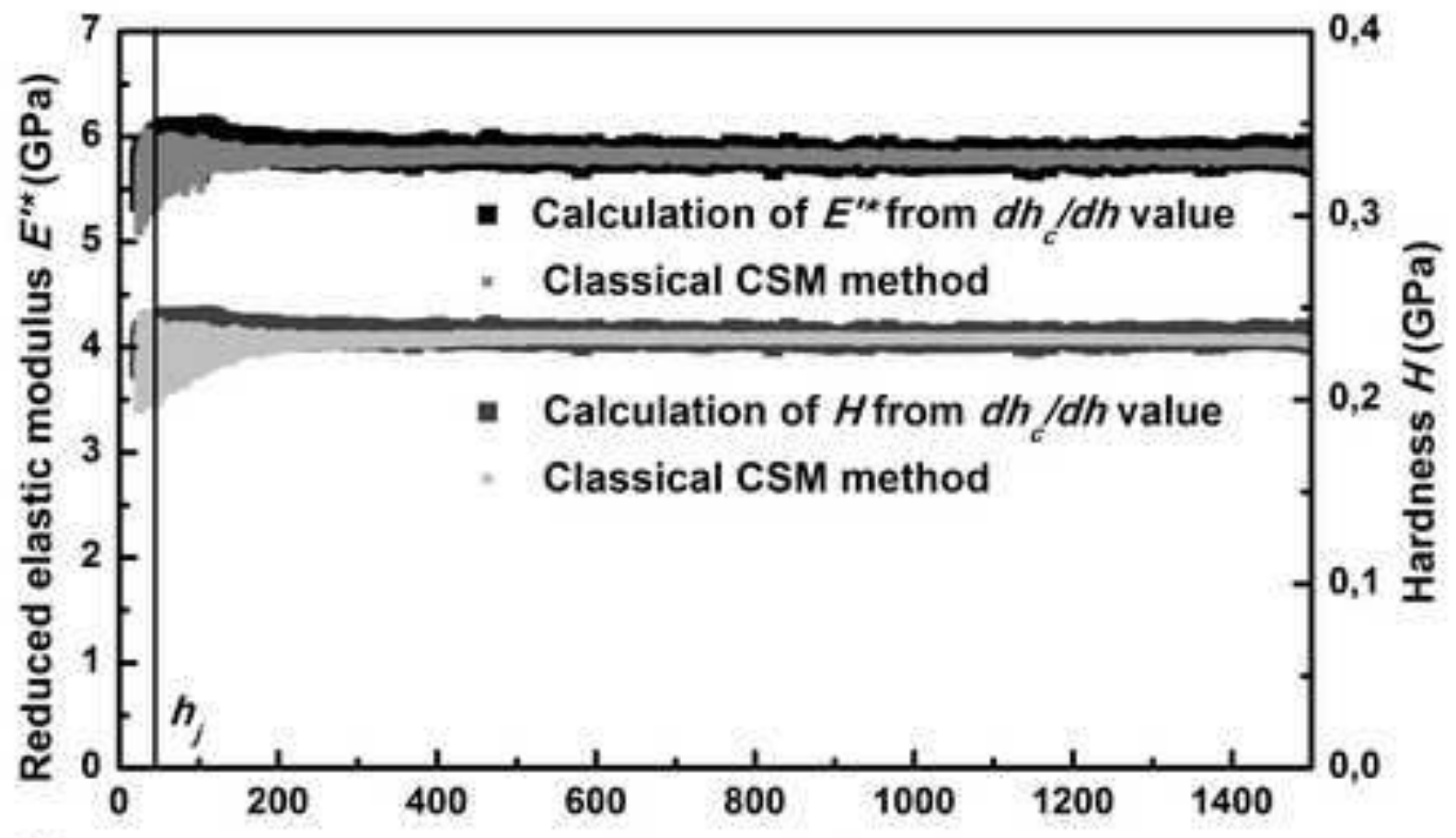

b)

Indentation depth $h(\mathrm{~nm})$ 
임
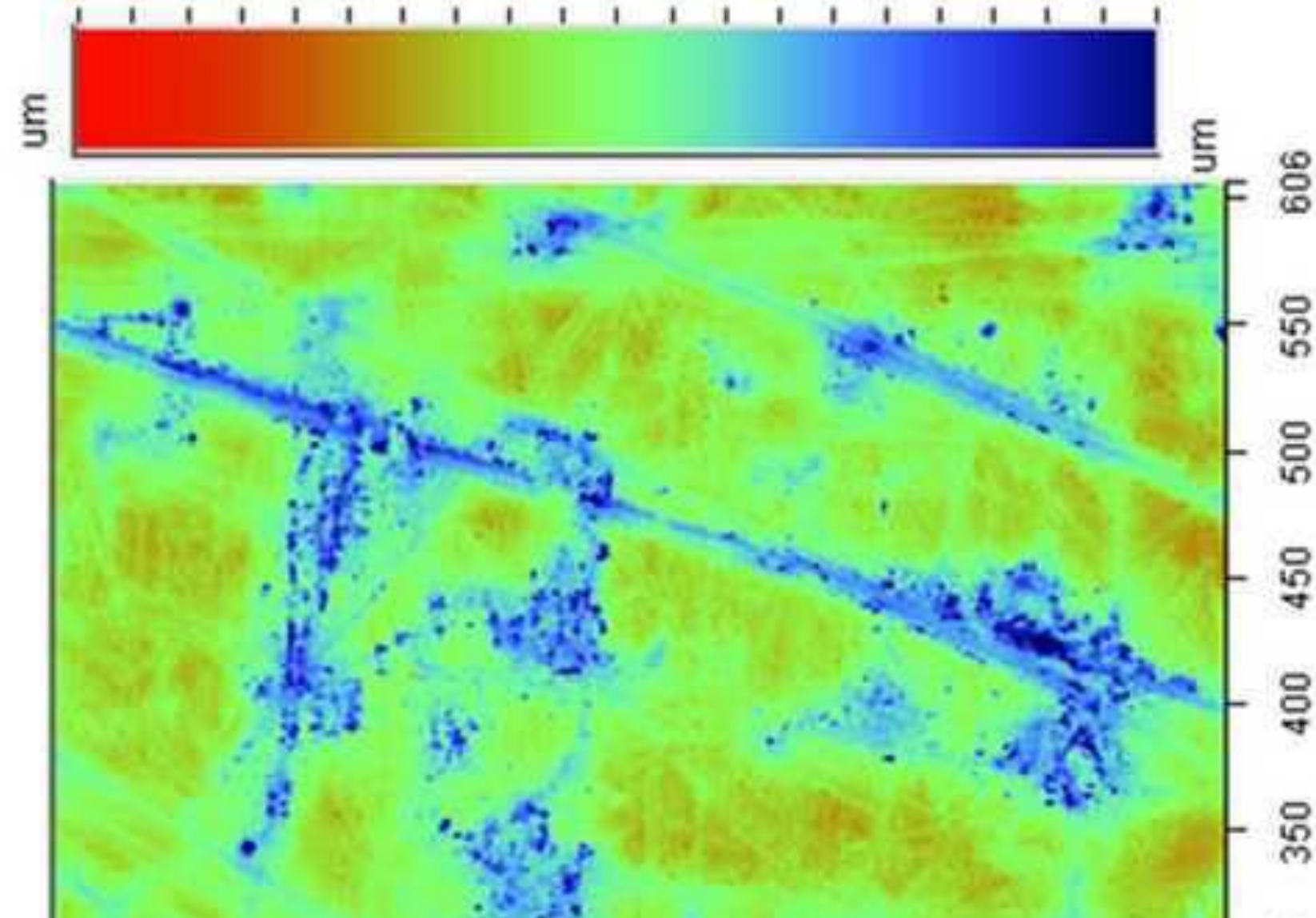

$c$

음 
Fig. 7

Accepted Manuscript
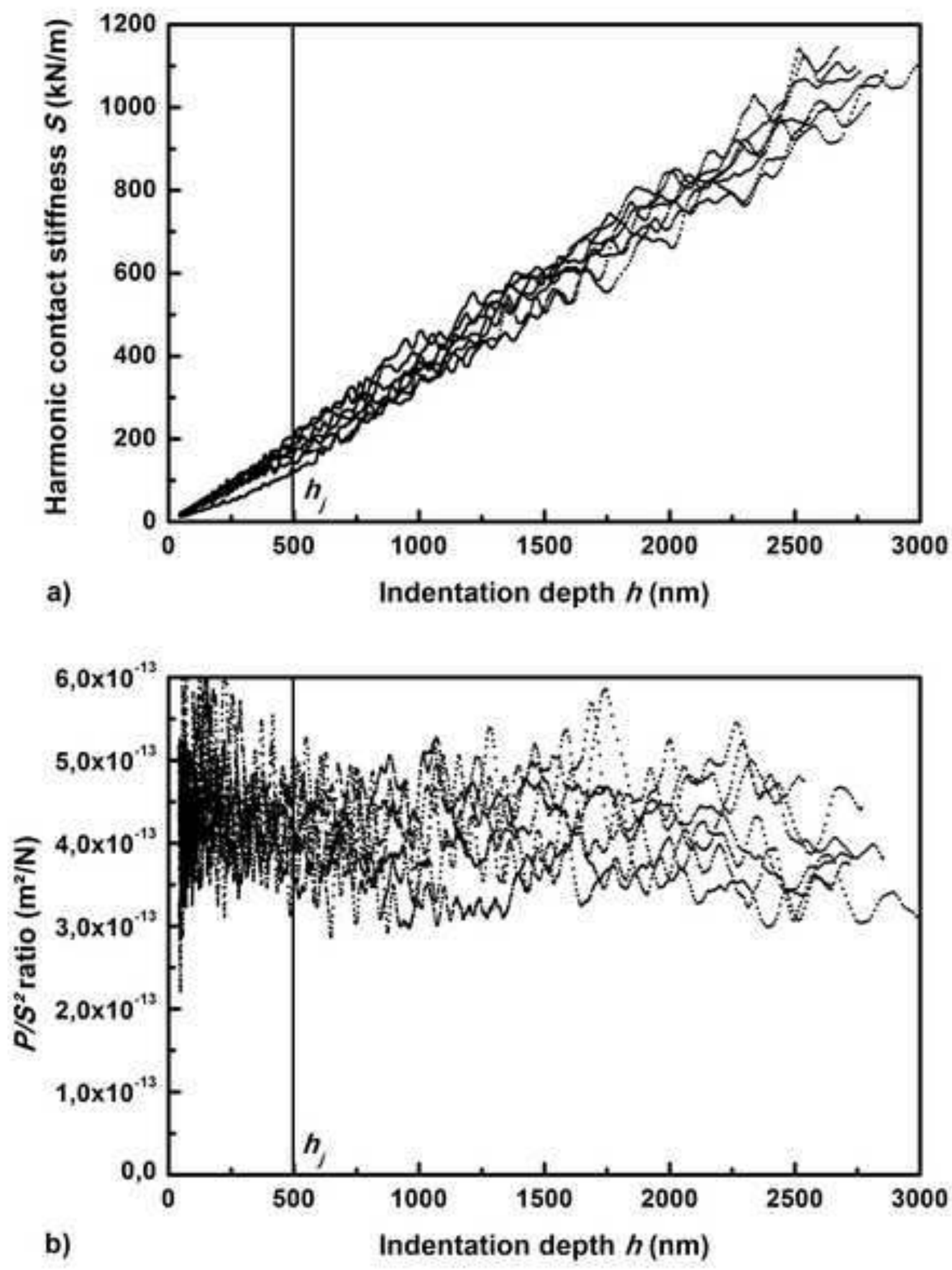


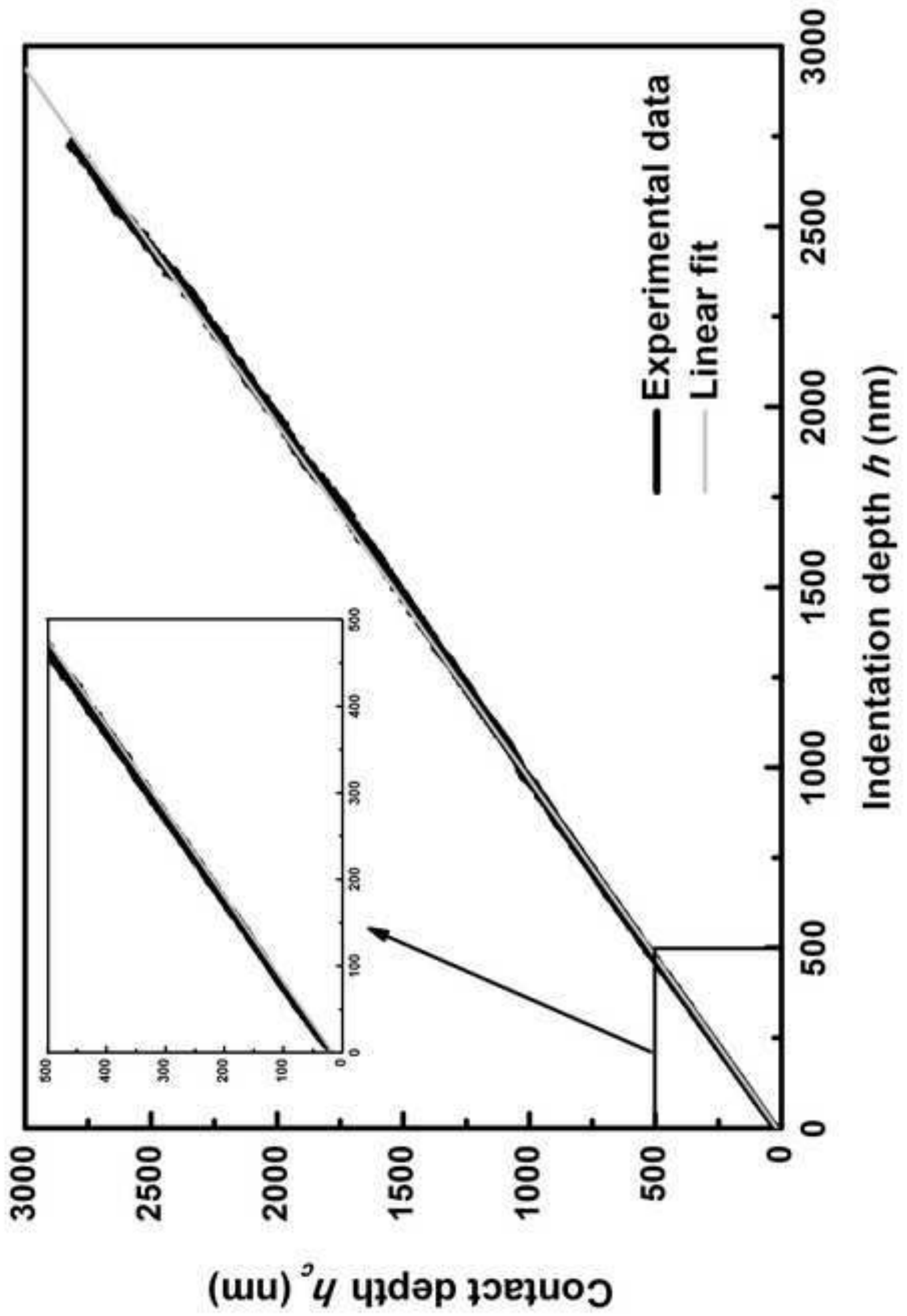

$\infty$ 
Fig. 9
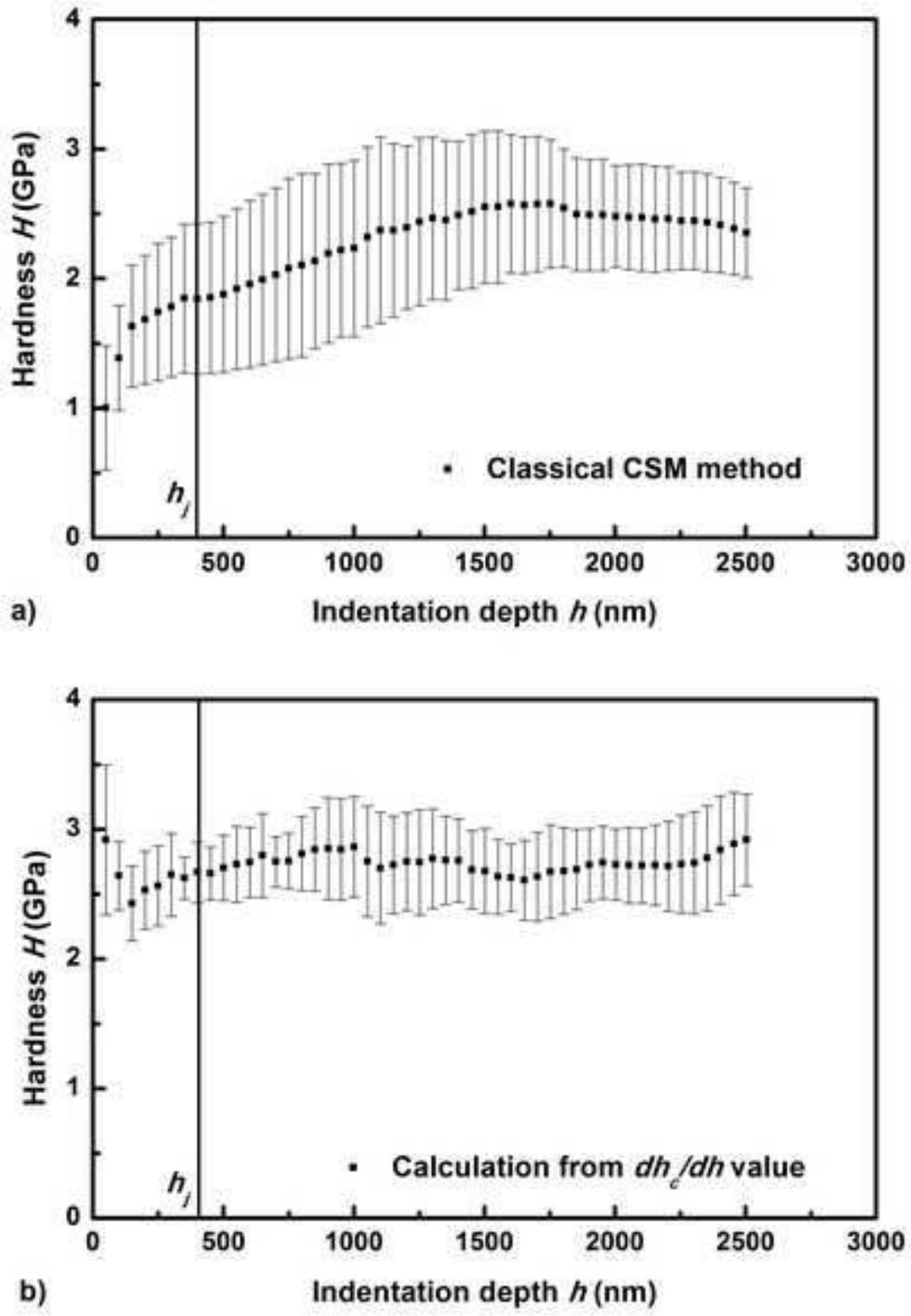
Fig. 10

Accepted Manuscript
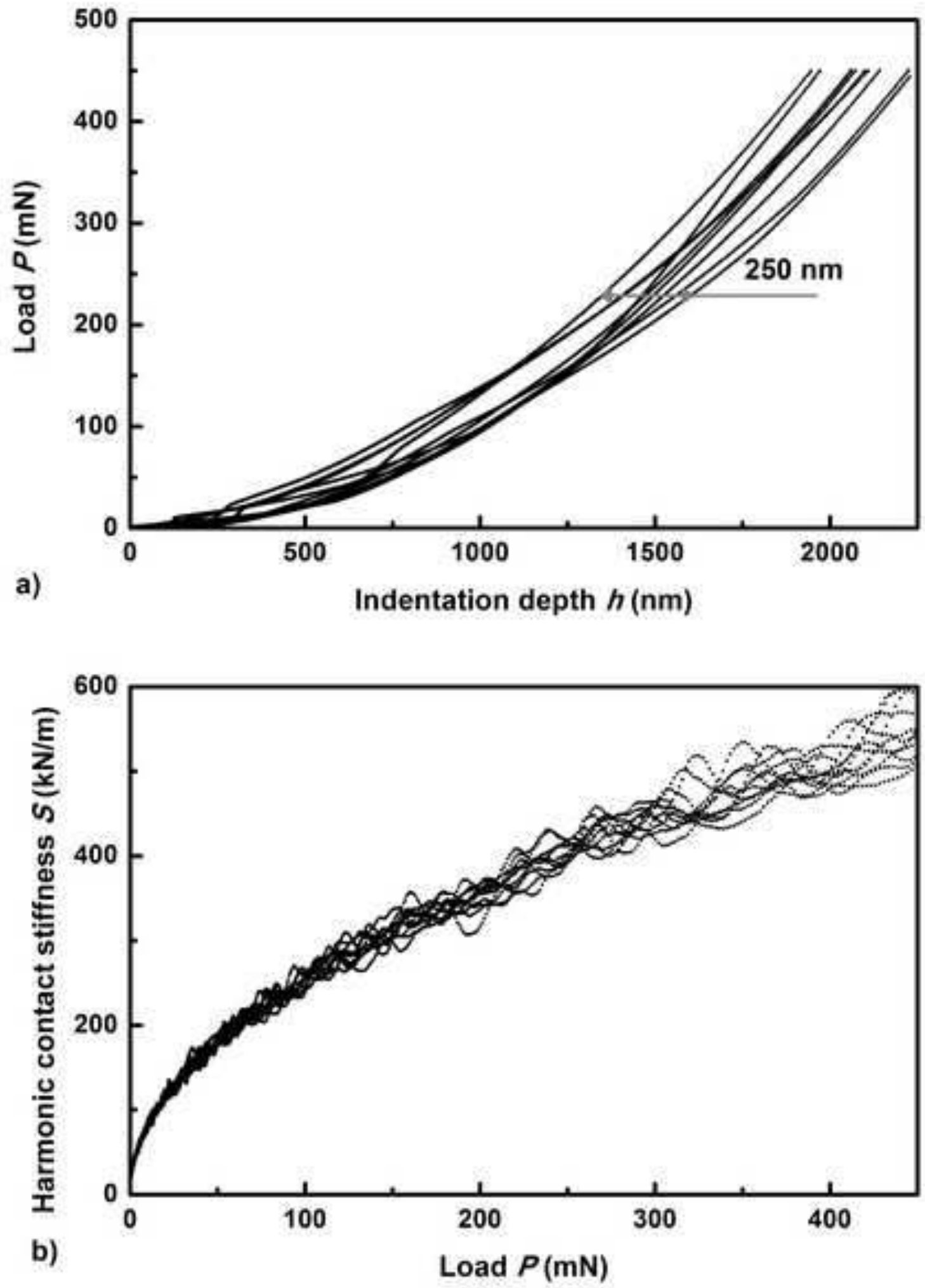

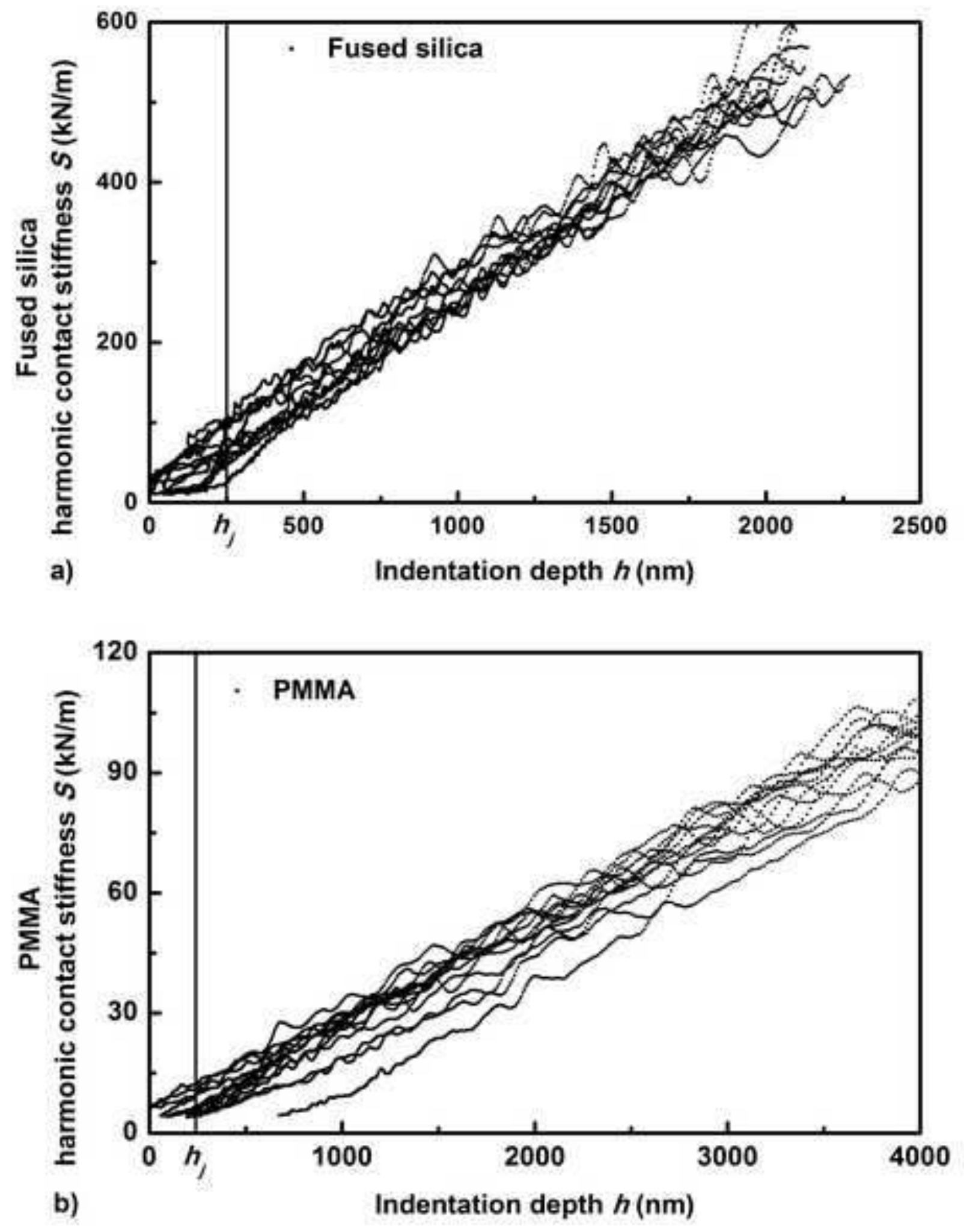

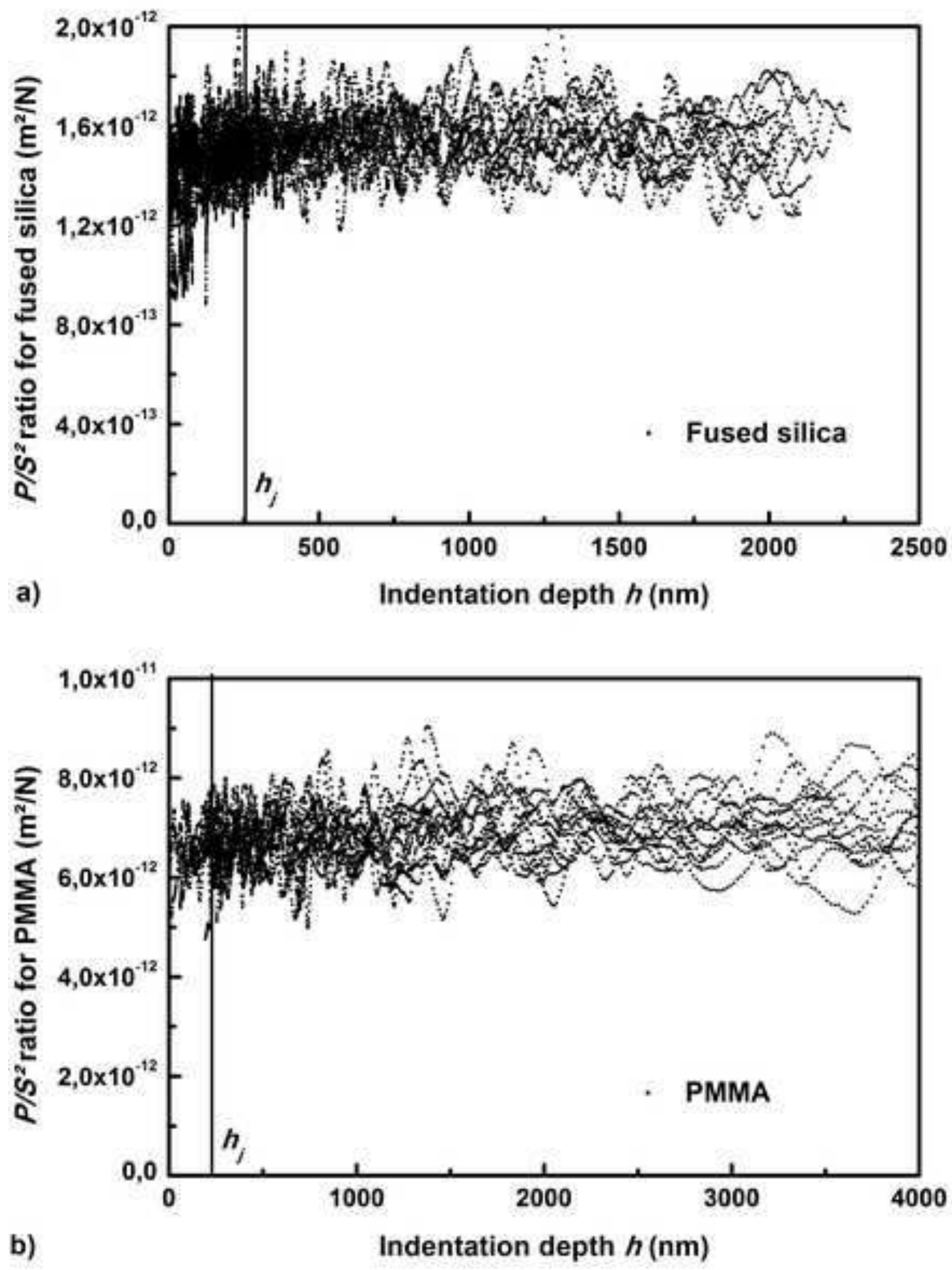
Fig. 13
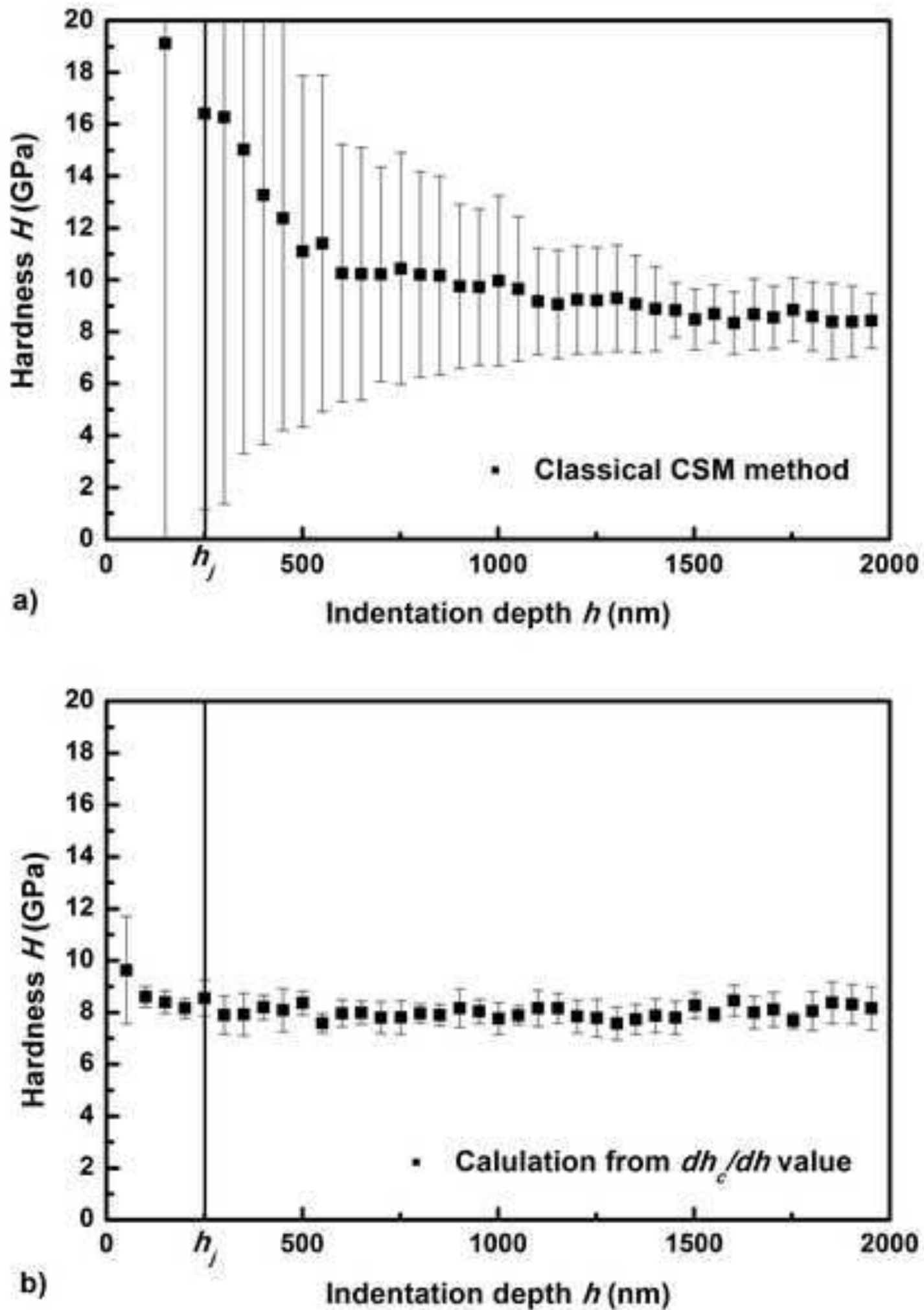
Fig. 14
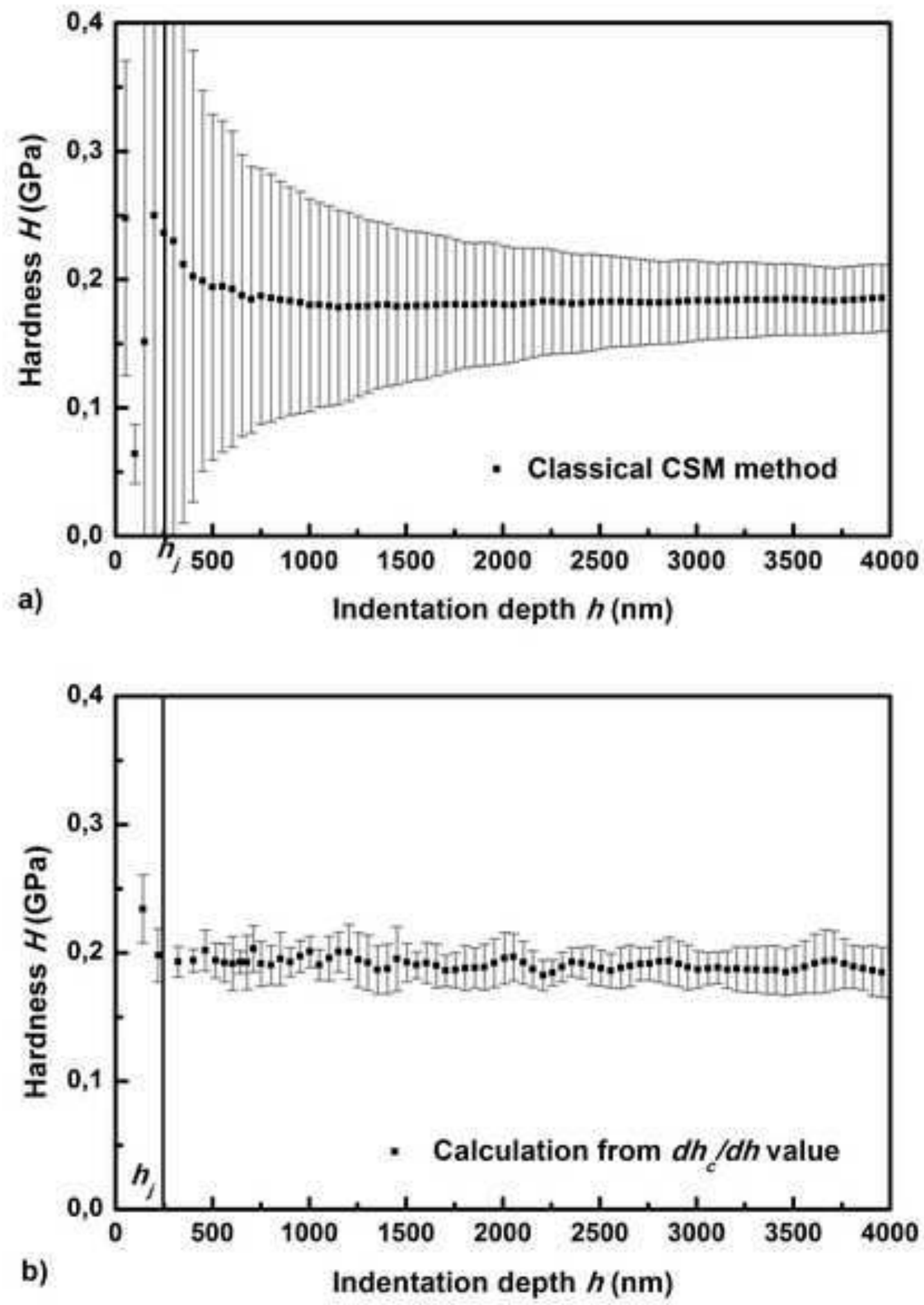


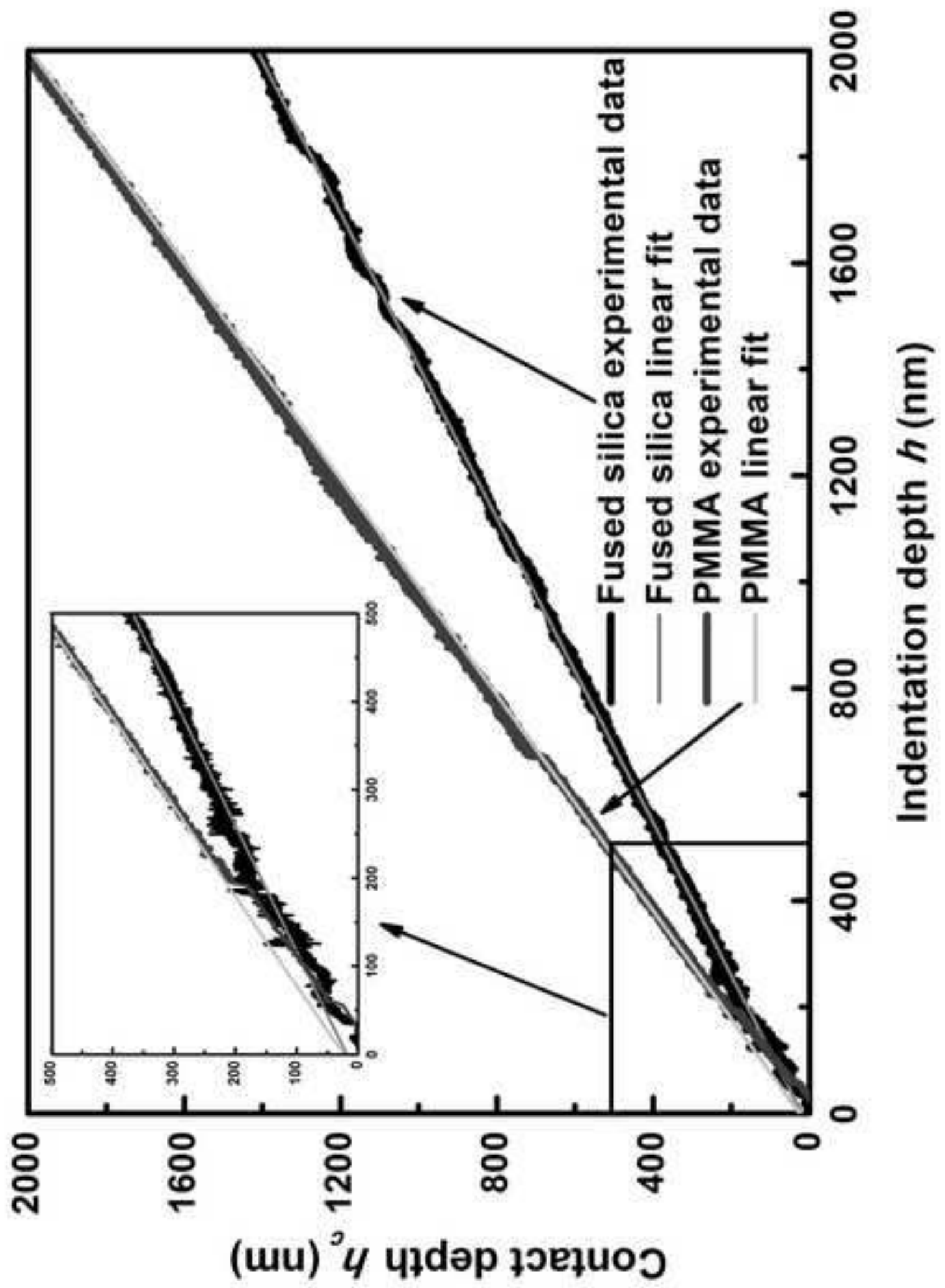

